\title{
Legal implications of data sharing in biobanking research in low-income settings: The Nigerian experience
}

\author{
S O Akintola, LLB, BL, LLM, PhD \\ Department of Private and Property Law, Faculty of Law, University of Ibadan, Nigeria
}

Corresponding author: SO Akintola (simiakintola@yahoo.com)

\begin{abstract}
It is increasingly recognised that effective and appropriate data sharing in biobanking research requires the development of models of good data-sharing policy capable of ensuring that the rights and privacy interests of participants are protected. However, the effectiveness and efficacy of biobank research depend on data and samples. In the same vein, making such data available to the research community generates tension between two important goals: advancing scientific goals, and protecting the individual privacy interests of the tissue source. More critically, data sharing requires the development of models that promote an environment in which privacy rights and interests of participants are protected throughout the lifecycle of biobank initiatives. Many ethical issues are raised when genomics research is conducted on populations characterised by lower average income and literacy levels, such as populations included in lower-middle income countries (LMICs). These issues are further exacerbated in Nigeria by cultural and religious inflections. In this paper, to analyse the implications of data sharing within the legal framework of an LMIC, an analysis of existing laws in Nigeria was conducted. It was discovered that there were no provisions relating directly to data sharing, and its governance framework could only be gleaned from the patchwork of laws on privacy and confidentiality in Nigeria. There is a need for ethical guidelines in Nigeria to be adapted to the changing landscape of science, which increasingly involves storage and secondary use of samples and data. Current laws are inadequate for the challenges presented by biobanking.
\end{abstract}

SAfr J Bioethics Law 2018;11(1):15-19. DOI:10.7196/SAJBL.2018.v11i1.601

There are ethically sound reasons for research to be conducted on diseases affecting populations with lower average income and literacy levels. Despite evident global inequalities existing in health measures such as mortality, quality of life and disease incidence, ${ }^{[1]}$ only a small proportion of medical research focuses on the problems primarily affecting the world's poorest people. ${ }^{[2]}$ It has been argued that applying the methods of genomics/biobanking research to these diseases is one way to address this imbalance..$^{[3]}$ Increasingly, biobanks have become a strategic tool in the field of biotechnology and genomics. In fact, the current century has been referred to by Francis Collinsas the 'genome era', both in science and in medicine..$^{[4]}$ Authorities in many European countries, including the UK biobank ${ }^{[5]}$ and the German National Ethics Council ${ }^{[6]}$ have noted the potential of biobanks for the identification of causes and the treatment of diseases. Although the definition of 'biobank' is not settled, and is multifaceted, it usually refers to a large collection of human biological tissue specimens and related data. ${ }^{[7]}$

Biobanks have, over the years, become an important means of gaining further understanding of the multifactorial nature of diseases. ${ }^{[8]}$ Biobanks, as large collections of both tissue samples and data, serve as a platform for enabling the sharing of samples and data for research, which will ultimately lead to improved health outcomes and personalised medicine. ${ }^{[9]}$ Underpinning the significance of data sharing in biobank research is a growing call for its recognition as a priority for the success of research, ${ }^{[10]}$ particularly in the context of biobanking research where tissue samples in the form of DNA, cell lines, tissue, plasma, medical information and blood samples have become essential tools for research and analysis, to seek and identify biomarkers and drug targets for diseases. However, sharing data and samples in genomic research via biobank platforms raises a number of legal and ethical challenges, regardless of where it is carried out. ${ }^{[1]}$ Some of these issues include consent, ${ }^{[12]}$ privacy ${ }^{[13]}$ and the collection, storage and release of genomic data. ${ }^{[14]}$ Despite the existence of a substantial and developing literature on the ethical and legal issues arising from sharing data in biobank research, this literature has as yet not adequately addressed the specific legal challenges presented by genomics research to the legal systems of lower-middle income countries (LMICs) such as Nigeria. De Vries et al. ${ }^{[15]}$ conclude that there is a need for guidelines in African countries to be adapted to the changing landscape.

The shift to genomic research and data sharing has been facilitated by funding from sponsors such as the USA, through the National Institutes of Health, and the UKWellcome Trust, which has encouraged collaboration in this regard. ${ }^{[16]}$ However, there has not been as much development in the legal frameworks and administration of justice in the field of genomic research. In discussing the development of a governance framework, at a global level that guarantees equity and fairness in biobank collaboration, Chen et al. ${ }^{[17]}$ explain that LMICs struggle with data sharing in genomic research for many reasons, including culture, religious beliefs and inadequate ethical and legal frameworks. In Nigeria, the focus of this paper, the legal framework on research is largely developmental, consisting of a patchwork of various legislation, which also does not augur well for consistency and precision in terms of determining the pervading jurisprudence for this area. 
The aim of this paper is to analyse and explore data sharing in biobank research in Nigeria as a low-income setting, focusing on the regulatory instruments that apply directly or tangentially to data sharing and biobank research. In analysing this, the article examines the legal implications of data sharing for research participants in lowincome settings such as Nigeria. It describes how data sharing tests current principles, and discusses ways of resolving these challenges. It should be noted, however, that this discussion is not exhaustive, as the legal and cultural implications of data sharing in biobanking research are broad.

\section{Biobanking research in Nigeria}

Nigeria has recently demonstrated its commitment to, and support for genomic research. It is one of only six countries (with Canada, China, Japan, the UK and the USA) involved in the International HapMap Project. Genomic research continues in Nigeria, and the Nigerian government, institutions and scientists are committed to genome science and research. Through the intervention of the national government, the Nigerian Biotechnology Development Agency $(\mathrm{NABDA})^{[18]}$ was established in Abuja, promoting biotechnology across disciplines in health and agriculture. Universities and research institutes also receive foreign grants to fund training and research on genomic technology and biobanking research, as in the case of the Institute of Medical Research and Training (IMRAT) in the Department of Virology, University of Ibadan, Nigeria. ${ }^{[19]}$ However, despite Nigeria being a pioneering member of the international consortium of genomics, the development of a legal regulatory framework in the country has been slow, ${ }^{[20]}$ in the sense that local capacity is struggling to keep pace with the regulatory and ethical challenges associated with genomic and biobank research.

For instance, although some of the nation's tertiary hospitals have tissue collections, the size and specific concentration of each repository are unknown. There is a biobank in the country, affiliated with the Institute of Human Virology in Nigeria (IHVN), known as the H3Africa (Human Heredity and Health in Africa) biobank. The H3Africa consortium is an international collaboration of scientists engaged in developing genomic research capacity in Africa. The biobank currently has 45358 samples in storage. IHVN also operates two repositories in Jos, a capital city in the Middle Belt of Nigeria, and Zaria, a major city in Kaduna state in Northern Nigeria. With respect to data sharing, informed consent and protection of health information, inter alia, the H3Africa biobank in Nigeria does not have an independent internal policy guideline, and therefore has to rely on those issued by appropriate authorities such as the National Health Research Ethics Committee (NHREC) in Nigeria, and in some cases the H3Africa consortium. Nonetheless, remarkable progress has been recorded in terms of the operation of the biobank. ${ }^{[20]}$ At present, the three biorepositories can support long- or short-term storage of samples that require -20 or $-80^{\circ} \mathrm{C}$ storage, and the biorepository at the National Tuberculosis and Leprosy Training Centre, Kaduna, supports the storage of TB isolates and other Mycobacteria. ${ }^{[20]}$ The following paragraphs examine the Nigerian legal framework on privacy, data, data sharing and human rights, to evaluate the relationship between data sharing and the laws in Nigeria. The Nigerian legal framework on privacy and data sharing includes statutes, case law, policies and guidelines.

\section{Privacy and the Nigerian Constitution}

Generally, data sharing is the practice of making data used for scholarly research available to other investigators. In genomic research, data sharing is a significant characteristic that allows secondary use of data in future, unspecified research. In this regard, data sharing poses several problems with respect to trust, privacy and uncontrolled secondary use of data, among other issues. ${ }^{[2]}$ Protection of individual privacy interests is governed by legal instruments in most democracies of the world. Although privacy is not an absolute right, derogating or interfering with this right must be justified by law as being in the public interest. In Nigeria, the 1999 Constitution of the Federal Republic of Nigeria ${ }^{[22]}$ provides for a fundamental human right to privacy in the following terms:

'The privacy of citizens, their homes, correspondence, telephone conversations and telegraphic communications is hereby guaranteed and protected.'

From the above, although there is no express mention of genomic or biobanking research, it is evident that Nigeria recognises and protects the right of all its citizens to privacy. It is arguable that sharing personal data as correspondence, electronically or via telecommunication, without the consent of the individual, can infringe an individual's right to privacy.

\section{National Information Technology Data Agency Guidelines}

Section 2 of the National Information Technology Data Agency (NITDA) guidelines requires that a data controller shall protect the privacy of natural persons with respect to the collection and processing of personal data, in accordance with their prescription. It also requires that data processing shall not take place without the consent of the data subject, who in this case is a Nigerian citizen. The NITDA is the national authority responsible for planning, developing and promoting the use of information technology in Nigeria. It is the body saddled with the responsibility of issuing guidelines that prescribe the minimum data-protection requirements for the collection, storage, processing, management, operation and technical controls of information. The guidelines regulate all organisations or persons that control, collect, store and process personal data of Nigerian residents within and outside Nigeria, for the protection of a specific category of data commonly known as personal data, or object-identifiable information. ${ }^{[23]}$

\section{The Freedom of Information Act, $2011^{[24]}$}

The Freedom of Information Act, 2011 is:

'an Act to make public records and information freely available, provide for public access to public records and information, protect public records and information to the extent consistent with the public interest and the protection of personal privacy, protect serving public officers from adverse consequences for disclosing certain official information and establish procedures for the achievement of those purposes and related purposes thereof.'25]

The Act deals with information in the custody of public institutions, which may include personal and genetic data such as that contained in national biobanks. It would appear that the objective of the Act is 
to provide access to public information that the Official Secrets Act, $1962^{[26]}$ hitherto withheld from Nigerians. Again, providing access or sharing data creates an inherent conflict between the right to privacy on the one hand, and the right to know on the other. The reason for this potential conflict is evident: laws of data protection and privacy are primarily concerned with the restriction of disclosure of information, while freedom of information laws, by design, are meant to facilitate general access to information. ${ }^{[2]}$ Even though the Nigerian Freedom of Information Act ${ }^{[28]}$ does not specifically cover genetic information, it can be safely deduced that genetic information in national biobanks may be within the purview of the Official Secrets Act. ${ }^{[29]}$ Other than these deductions, there is no judicial interpretation on record of this in relation to genetic information.

\section{Other attempts at legislation}

There have been several attempts at legislating data protection in the recent past by the Nigerian legislature. Apart from the Nigerian Cyber Crime Act, 2015, several Bills have been drafted that address areas relating to data sharing in Nigeria; however, to date, most have not yet been passed into law. Some of these are: the Computer Security and Critical Information Infrastructure Protection Bill, 2005; ${ }^{[30]}$ the Cyber Security and Data Protection Agency Bill, 2008; ${ }^{[3]]}$ the Nigeria Computer Security and Protection Agency Bill, 2009; ${ }^{[32]}$ and the Computer Misuse Bill (Amendment) Bill 2010. ${ }^{[33]}$

\section{Implications of data sharing}

While biobanking research presents both legal and ethical challenges regardless of where it is conducted, prospective participants in LMICs are more likely to be affected by them, given the inadequate legal framework surrounding data sharing. ${ }^{[34,35]}$ Coupled with this is the fact that a greater number of the population are poor and have limited access to healthcare, education and other resources. This means that the carrying out of research in these settings invariably presents challenges of a different order than those in higher-income countries. In the following section, the paper explores some of the challenges presented by genomic research for law relating to privacy and obtaining valid consent, both generally and in LMICs.

\section{Informed consent}

When individuals provide information about themselves for medical treatment, or even medical research, the parameters of informed consent are relatively clear, in the sense that there is a presumption that such consent was obtained from a competent research subject or patient who was given adequate disclosure of information at the point of recruitment. ${ }^{[36]}$ In other words, individuals must be told what uses their information and samples will be put to, and standard notices of privacy practices inform patients that their information may be used in lieu of treatment payment, or healthcare operations. In biobank research, however, it is usually not as clear-cut. The possibility of future use in research is a characteristic of biobank/ genomic research, posing the question of the permissibility of later research use. In addition to this, designing consent processes for biobanking/genomic research in low-income settings presents peculiar challenges, such as language and cultural inflexions. ${ }^{[3]}$ For instance, there are difficulties in providing information in a comprehensible manner to participants in genomics research, or finding synonyms in local dialects to convey information necessary to give consent. ${ }^{[38]}$ In genomics, these challenges are presented by the need to explain concepts such as 'genetics', 'genomics' and 'data release', and the reasons underlying the need to collect large quantities of samples and data from healthy populations for controls. ${ }^{[39]}$

Aside from this, one of the peculiarities of genomic research is that the data produced have the potential to affect others, in the sense that such data can be informative about people other than the research participant. Even where personal identifiers are removed from genetic datasets, there may arguably be limited risk of participant identification. Yet even where this is the case, there remains a possibility that unwanted information about populations, communities or families can still be revealed. This raises questions of privacy protection not only for the research participant, but also for communities and population groups. For instance, a genomewide association study (GWAS) can reveal that a stigmatising condition is more likely to occur in one community than another. In that sense, it is possible to generate research results that could stigmatise communities, and thus have adverse effects on them socially. It is therefore important to consider this when generating informed-consent documents or processes for communities such as this.

Community engagement through a community advisory board $(C A B)$, as envisaged by the Nigerian National Code of Health Research Ethics (NCHRE), ${ }^{[40]}$ is intended to be a way to accommodate and respect the rights of members of a community engaged in research. Under the code, the NHREC is saddled with the responsibility of ensuring that communities engaged in research are protected from exploitation. The precise definition of exploitation is a subject of debate, and the code does not define what it means by exploitation. Nonetheless, from its tone and the provisions, it seems to refer to exploitation in the sense of taking unfair advantage of community members. ${ }^{[4]]}$ Therefore, collaborative involvement of a $C A B$, to provide a forum for members of the community to share their views on ethical issues that the proposed research raises, is considered a way to reduce the potential for exploitation. In relation to data sharing, it would be difficult, if not impossible, for members of the community on the $C A B$ to effectively share views on data that are yet to be collected, analysed and shared. It is doubtful whether these members are sufficiently knowledgeable to engage in discussion on implications of global data sharing in light of technological advancements in the field of genomics and data analysis. Laudable as this provision on $C A B s$ is, the $C A B$ model has been criticised for being prone to limitations such as a lack of power and technical knowledge, and for failing to adequately protect the privacy interests of tissue sources in population studies, and subsequent data sharing. ${ }^{[42,43]}$

\section{Privacy and confidentiality within the context of African communitarian values}

Privacy protects individuals from unwarranted access to the person; confidentiality protects information about the person from unwanted use or disclosure. Both have been thought to raise special issues regarding genomic information. Privacy in the fabric of the African ethos and culture raises questions that are different from those in Western thought. In African communities, there is a strong awareness 
of one's existence and relationship with others in the community, a strong sense of 'social self'. The support of others is seen as more important than one's capacities to achieve one's own existential ends, hence the value placed on corporate existence. According to Menkiti, ${ }^{[44]}$ a crucial distinction therefore exists between the African view of man and the view in Western thought: in the African view, it is the community that defines the person as a person, not necessarily an isolated static quality of rationality, will, or memory.

This African social ethic is expressed in many maxims, proverbs, extended family relationships and communal living, which all emphasise the importance of the values of mutual helpfulness, collective responsibility, co-operation, interdependence and reciprocal obligations. The extended family setting, for instance, reflects an ethic of mutual help, survival and care for each other. ${ }^{[8]}$

The social, communal or relational character of the African prescribes a social ethic rather than one of individualism. ${ }^{[45]}$ Individualistic ethics that focus on the welfare and interests of the individual are seldom regarded in African moral thought. In African cultures, such as in Nigeria, the boundaries of personal privacy are narrower. Extended family and communal living tends to blur demarcations of personal and spatial privacy within the family setting. The extended family setting is essentially a communal one in which everyone looks out for the other, including in matters relating to health and welfare. ${ }^{[46]}$ Research reveals that when conducting genetic screening in Africa, issues of confidentiality are not limited solely to the individual participant, but extend to family members who are still living, and also, critically, the interests of departed souls and those yet unborn. ${ }^{[4]]}$

In an African community, the interests of the community or extended family may be more important than the interests of the individual. This is because communities may bear risks that are not simply aggregates of the risks to individuals, and, in an African culture, community participation is a fundamental aspect of individual decisions. ${ }^{[48]}$

Thus the decision to participate in future unspecified research where data associated with the community may be shared may be that of the community as a whole, in conjunction with the tissue source. Despite the fact that the margin of privacy is narrower in African communities, however, the concept of privacy within communities is not discounted. Privacy, as the concept of being left alone to make choices best suited to the individual, remains the norm in these communities. The application of privacy to the individual, as opposed to a corporate norm, is the point of digression from Western thought in African communities. ${ }^{[38]}$ According to de Vries et al. ${ }^{[39]}$ data sharing and research in communities with a communal ethos present important ethical challenges that have been shown to differ from those with an individualistic Western ethos in significant ways.

\section{Conclusion and recommendations}

There is a need for more research on the legal and ethical implications of data sharing for Nigerians and other citizens of LMICs. Data on African communities and localities where re-identification is possible should be secured. Genomic data need to be secured with up-todate security software back-up, and this should be made a legal requirement. Currently, most laws relating to data sharing in Nigeria fail to adequately describe biobanking research or genomics.
The perspectives of Nigerians and other citizens of LMICs on data sharing policies as they exist are sparsely represented in the literature, and therefore more social science research should examine this aspect.

Community involvement should be as important as individual consent in these settings, yet it should not override or substitute for an individual's choice as to whether or not to participate in future, unspecified research. ${ }^{[49]}$

Identifying and recognising the ethical challenges that arise in diverse, though interconnected, ways in different research settings is a step in the right direction. However, this requires more legal and social science-based research, to establish a proper understanding of the legal jurisprudence and perspectives of relevant low-income settings regarding what constitutes legally acceptable and ethical data sharing.

\section{Acknowledgements. None.}

Author contributions. Sole author.

Funding. None.

Conflicts of interest. None.

1. Berlinguer G. Bioethics, health, and inequality. Lancet 2004;364 (9439):1086-1091. https://doi.org/10.1016/s0140-6736(04)17066-9

2. World Health Organization. Global Forum for Health Research: The 10/90 report on Health Research 2001 - 2002. Geneva: WHO, 2002. http://announcementsfiles. cohred.org/gfhr_pub/assoc/s14792e/s14792e.pdf (accessed 7 September 2017).

3. McGuire AL, Beskow LM. Informed consent in genomics and genetic research. Ann Rev Genomics Hum Genet 2010;11(1):361-381. https://doi.org/10.1146/annurevgenom-082509-141711

4. Chalmers D. Genetic research and biobanks. In: Dillner J, ed. Methods in Biobanking New York: Springer International, 2011:1-37. https://doi.org/10.1007/978-1-59745423-0

5. Sudlow C, Gallacher J, Allen N, et al. UK Biobank: An open access resource for identifying the causes of a wide range of complex diseases of middle and old age. PIOs Med 2015;12(3):e1001779. https://doi.org/10.1371/journal.pmed.1001779

6. German National Ethics Council (ed.) Biobanks for research: Opinion. Berlin German National Ethics Council, 2004. http://www.ethikrat.org/files/der_opinion human-biobanks.pdf (accessed 6 July 2017).

7. Hewitt R, Watson P. Defining biobank. Biopreservation Biobanking 2013;11(5):309 315. https://doi.org/10.1089/bio.2013.0042

8. Kigongo JK. The relevance of African ethics to contemporary African society In: Dalfovo AT, ed. Ethics and Human Rights Development in Africa: Ugandan Philosophical Studies III, Africa; Cultural Heritage and Change Series II. Africa. Washington DC: 2002,8:51-66.

9. Swede $\mathrm{H}$, Stone $\mathrm{CL}$, Norwood AR. National population-based biobanks for genetic research. Genetics Med 2007;9(3):141-149. https://doi.org/10.1097/ gim.0b013e3180330039

10. Parker M, Bull S. Sharing public health research data: Towards the development of ethical data-sharing practice in low and middle income settings. J Empir Res Hum Res Ethics 2015;10(3):17-24. https://doi.org/110.1177/1556264615593494

11. Kaye J, Boddington P, De Vries J, Hawkins N, Melham K. Ethical implications of the use of whole genome methods in medical research. Eur J Hum Genet 2009;18(4):398-403. https://doi.org/10.1038/ejhg.2009.191

12. McGuire AL, Caulfield T, Cho MK. Research ethics and the challenge of whole genome sequencing. Nat Rev Genet 2008;9(2):152-156. https://doi.org/10.1038/ $\operatorname{nrg} 2302$

13. Lunshof JE, Chadwick R, Vorhaus DB, Church GM. From genetic privacy to open consent. Nat Rev Genet 2008;9(5):406-411. https://doi.org/10.1038/nrg2360

14. Chokshi DA, Parker M, Kwiatkowski DP. Data sharing and intellectual property in a genomic epidemiology network: Policies for large-scale research collaboration. Bull World Health Organ 2006;84(5):382-387. https://doi.org/10.2471/blt.06.029843

15. De Vries J, Munung SN, Matimba A, et al. Regulation of genomic and biobanking research in Africa: A content analysis of ethics guidelines, policies and procedures from 22 African countries. BMC Med Ethics 2017;18(1):1-9. https://doi.org/10.1186/ s12910-016-0165-6

16. Kaye J. The tension between data sharing and the protection of privacy in genomics research. Annu Rev Genomics Hum Genet 2012;13(1):415-431. https:// doi.org/10.1146/annurev-genom-082410-101454 
17. Chen $H$, Pang T. A call for global governance of biobanks. Bull World Health Organ 2015;93(2):113-117. https://doi.org/10.2471/blt.14.138420

18. Nigerian Biotechnology Development Agency. http://www.nabda.gov.ng/ (accessed 11 September 2017).

19. Akintola S, L Callier S, O Ogundiran T. Personalizing medicine in Nigeria by tailoring the research process: Points to consider for genomic research. Curr Pharmocogenomics Personalized Med 2013;11(4):267-273. https://doi.org/10.2 174/18756921113119990010

20. Nnamuchi O. Biobank/genomic research in Nigeria: Examining relevant privacy and confidentiality frameworks. J Med Ethics 2015;43:776-904. https://doi. org/10.1111/jlme.12319

21. Egea M, Matteucci I, Mori P, Petrocchi M. Definition of data sharing agreements. In: Felici M, Fernandez-Gago C (eds.) Accountability and Security in the Cloud. Basel: Springer International Publishing, 2015:248-272.

22. Constitution of the Federal Republic of Nigeria, 1999. Section 37, Cap. C23 LFN

23. Belo-Osagie, Udoma U. Data Privacy Protection in Nigeria. Elexica, Simmons \& Simmons, 2015. http://www.uubo.org/downloads/SIMM0715001-Data_Privacy_ Protection_in_Nigeria.pdf (accessed 6 July 2017).

24. Federal Republic of Nigeria. Freedom of Information Act, 2011. Cap F36, LFN, 2004

25. Preamble of the Freedom of Information Act, 2011. https://www.cbn.gov.ng/ FOI/Freedom\%20Of\%20Information\%20Act.pdf (accessed 11 September 2017).

26. Federal Republic of Nigeria. Official Secrets Act, 1962. Cap. O3, LFN, 2004

27. Federal Republic of Nigeria. Freedom of Information Act, 2011. Section 14(1)(a) and 15(4).

28. Federal Republic of Nigeria. Freedom of Information Act, 2011. Cap F36, LFN, 2004

29. Jemilohun BO, Akomolede TI. Regulations or legislation for data protection in Nigeria? A call for a clear legislative framework. Glob J Pol Law Res 2015;3(4):1-16.

30. Federal Republic of Nigeria. Computer Security and Critical Information Infrastructure Protection Bill, 2005.

31. House of Representatives, Federal Republic of Nigeria. Order Paper. Cyber Security and Data Protection Agency (Establishment etc.) Bill, 2008. http://www.nass.gov. $\mathrm{ng} /$ document/download/2419 (accessed 6 July 2017).

32. A Bill for an Act to Establish a Legal and Institutional Framework for Securing Computers and Networks and Proetcting Critical Information Infrastructure in Nigeria. http://www.nass.gov.ng/document/download/1230 (accessed 6 July 2017).

33. Federal Republic of Nigeria. A Bill for an Act to Make Provision for the Safety and Security of Electronic Transactions and Information Systems. http://nass.gov.ng/ document/download/1168 (accessed 6 July 2017).

34. De Vries J, Pepper M. Genomic sovereignty and the African promise: mining the genome for the benefit of Africa. J Med Ethics 2012;38(8):474-478. https://doi. org/10.1136/medethics-2011-100448

35. Parker M, Bull SJ, de Vries J, Agbenyega T, Doumbo OK, Kwiatkowski DP. Ethical data release in genome-wide association studies in developing countries. PLOS Med 2009;6(11):1000143. https://doi.org/10.1371/journal.pmed.1000143
36. Gikonyo C, Bejon P, Marsh V, Molyneux S. Taking social relationships seriously: Lessons learned from the informed consent practices of a vaccine trial on the Kenyan Coast. Soc Sci Med 2008;67(5):708-720. https://doi.org/10.1016/j. socscimed.2008.02.003

37. Tindana $\mathrm{PO}$, Kass $\mathrm{N}$, Akweongo $\mathrm{P}$. The informed consent process in a rural African setting: A case study of the Kassena-Nankana District of Northern Ghana. IRB: Ethics Hum Res 2006;28(3):1-6.

38. Molyneux CS, Peshu N, Marsh K. Understanding of informed consent in a low-income setting: Three case studies from the Kenyan Coast. Soc Sci Med 2004;59(12):2547-2559. https://doi.org/10.1016/j.socscimed.2004.03.037

39. De Vries JBS, Doumbo O, Ibrahim M, Mercereau-Puijalon O, Kwiatkowski D, Parker M. Ethical issues in human genomics research in developing countries. BMC Med Ethics 2011;12(5):1-10. https://doi.org/10.1186/1472-6939-12-5

40. National Health Research Ethics Committee, Nigeria. Nigerian National Code of Health Research Ethics, 2007. Section E (r) (3) (d) http://www.nhrec.net/nhrec/ NCHRE_Aug\%2007.pdf (accessed 7 September, 2017).

41. Pratt B, Lwin KM, Zion D, Nosten F, Loff B, Cheah PY. Exploitation and community engagement: Can Community Advisory Boards successfully assume a role minimizing exploitation in international research? Dev World Bioethics 2015;15(1):18-26. https://doi.org/10.1111/dewb.12031

42. Strauss RP, Sengupta S, Quinn SC, et al. The role of community advisory boards: Involving communities in the informed consent process. Am J Pub Health 2001;91(12):1938-1943. https://doi.org/10.2105/ajph.91.12.1938

43. Slevin KW, Ukpong M, Heise L. Community Engagement in HIV Prevention Trials: Evolution of the Field and Opportunities for Growth. Seattle: Path Publications, 2008.

44. Menkiti IA. Person and community in African traditional thought. In: Wright RA ed. African Philosophy: An Introduction. 3rd ed. New York: University Press of America, 1984;171-181.

45. Ekpe CP. Social welfare and family support: The Nigerian experience. J Sociol Soc Welfare 1983;10(3):484-496.

46. Teffo $\sqcup$. Both/ubuntu as a way forward for contemporary South Africa. Word Action 1998;38(365):3-5.

47. Jegede AS. Culture and genetic screening in Africa. Develop World Bioethics 2009;9(3):128-137. https://doi.org/10.1111/j.1471-8847.2009.00259.x

48. Diallo DA, Doumbo OK, Plowe CV, Wellems TE, Emanuel EJ, Hurst SA. Community permission for medical research in developing countries. Clin Infect Dis 2005;41(2):255-295. https://doi.org/10.1086/430707

49. Hall AJ. Public health trials in West Africa: Logistics and ethics. IRB: Ethics Hum Res 1989;11(5):8-10. https://doi.org/10.2307/3564470 